\title{
Identificação de foco estratégico e de consistência entre fins e meios em empresas calçadistas do Estado de São Paulo
}

\author{
Identification of strategic focus and consistency between ends \\ and means in footwear companies in the State of São Paulo
}

\author{
Stella Jacyszyn Bachega ${ }^{1}$ \\ Moacir Godinho Filho²
}

\begin{abstract}
Resumo: O presente artigo apresenta os resultados de uma pesquisa que teve o objetivo de identificar, por meio de um survey nos polos calçadistas de Franca, Birigui e Jaú, a presença/ausência de foco estratégico nas empresas e a consistência/inconsistência entre fins e meios. O procedimento de pesquisa utilizado foi a pesquisa de avaliação, também conhecida como survey. Vinte e nove empresas, selecionadas por meio de amostragem probabilística e aleatória, participaram da pesquisa. Para tais identificações, utilizou-se o método desenvolvido por Godinho Filho e Fernandes (2009). Dentre os principais resultados, verificou-se que 69\% das empresas calçadistas entrevistadas encontram-se sem foco estratégico e 79,3\% dos respondentes apresentam inconsistência entre fins e meios. Além disso, $62,1 \%$ dessas empresas estão em ambas as situações (inconsistência entre fins e meios e ausência de foco estratégico). Este trabalho apresenta como contribuição o alerta para a existência de falta de foco estratégico e de situações de inconsistência entre fins e meios em empresas do setor calçadista. Essas informações são importantes para o setor coureiro-calçadista, que apresenta um histórico de crise, indicando a necessidade das empresas se reestruturarem estratégica e gerencialmente para encontrarem um 'norte' e, assim, sobreviverem neste ambiente cada vez mais dinâmico e competitivo.
\end{abstract}

Palavras-chave: Estratégia de produção. Indústria de calçados. Paradigmas de gestão da manufatura. Foco estratégico. Consistência entre fins e meios.

\begin{abstract}
This paper presents the results of a study that aimed to identify, by means of a survey in the footwear cluster of Franca, Birigui, and Jaú, the presence/lack of strategic focus on business and consistency/inconsistency between ends and means. The research procedure used was the survey. Twenty-nine companies, selected through probabilistic and random sampling, participated in the survey. The method developed by Godinho Filho and Fernandes (2009) was used. Among the main results, it was found that $69 \%$ of the footwear firms interviewed have no strategic focus and $79.3 \%$ of the respondents presented inconsistency between ends and means. Furthermore, $62.1 \%$ of those companies presented both inconsistency between ends and means and lack of strategic focus. This paper presents a contribution to the alert that there is lack of strategic focus and instances of inconsistency between ends and means in companies in the footwear industry. This information is important for the leather-footwear sector, which has a history of crisis, indicating the need for firms to restructure themselves strategically and managerially in order to survive in an increasingly dynamic and competitive business environment.
\end{abstract}

Keywords: Manufacturing strategy. Footwear industry. Paradigms for manufacturing management. Strategic focus. Consistency between ends and means.

\section{Introdução}

Uma definição de estratégia que seja aceita universalmente não é encontrada, apesar de existir enorme volume de literatura sobre o assunto. Segundo Ginsberg (1984 apud GIMENEZ, 2000), o termo estratégia é utilizado muitas vezes sem necessárias

clarificações, dificultando o desenvolvimento de abordagens integradoras, no que tange ao estudo de estratégia organizacional.

A palavra estratégia tem suas origens na área militar e, quando aplicada ao campo dos negócios,

\footnotetext{
${ }^{1}$ Departamento de Engenharia de Produção, Universidade Federal de Goiás, Campus Catalão - UFG-CAC, Av. Dr. Lamartine Pinto de Avelar, 1120, CEP 75704-020, St. Universitário, Catalão - GO, E-mail: stella@ dep.ufscar.br

${ }^{2}$ Departamento de Engenharia de Produção, Universidade Federal de São Carlos - UFSCar, Rod. Washington Luís, Km 235, CEP 13565-905, Monjolinho, São Carlos - SP, Brasil, E-mail: moacir@dep.ufscar.br
} 
denomina-se estratégia empresarial. Henderson (1998) advoga que a estratégia é a procura deliberada de um plano de ação que tem a função de desenvolver e ajustar a vantagem competitiva de uma organização. Segundo Mintzberg e Quinn (2001) e Mintzberg (1991), estratégia pode ser entendida como plano, manobra (ploy), padrão, posição e perspectiva, caracterizando os "cinco Ps" da estratégia.

Ao aplicar o termo estratégia à função produção, Skinner (1969) criou o conceito estratégia de manufatura, também conhecido como estratégia de produção e de operações. Uma estratégia de manufatura é um conjunto de planos e políticas por meio dos quais a companhia objetiva obter vantagens sobre seus competidores e inclui planos para a produção e a venda de produtos para um particular conjunto de consumidores (SKINNER, 1969). Contudo, conforme Slack et al. (2002), a estratégia de manufatura possui os propósitos de auxiliar as demais partes do negócio a contribuir para a estratégia e de cooperar, de forma direta, para os objetivos estratégicos do nível imediatamente superior na hierarquia.

Maiores detalhes sobre estratégia empresarial e estratégia de manufatura podem ser encontrados em Pereira, Sellitto e Borchardt (2010), Patah e Carvalho (2009), Riis et al. (2007), Hallgren e Olhager (2006), Harrison (2004), Ketokivi e Heikkilä (2003), Thompson Junior e Strickland III (2002), Oliveira (2001), Wright, Kroll e Parnell (2000), Zaccarelli (2000), Gupta (1999), Christensen (1999), Porter (1999), Mintzberg (1998), Henderson (1998), Porter (1997), Pires (1995), Corrêa (1993), Ansoff (1990), Porter (1989), Hayes e Wheelwright (1984), entre outros.

Sobreviver e prosperar no atual mercado, cada vez mais competitivo, representam um grande desafio às organizações. Estas devem procurar a obtenção de uma vantagem competitiva, em relação aos concorrentes, por meio de seus objetivos estratégicos (custo, qualidade, flexibilidade, confiabilidade e velocidade) $\mathrm{e}$, consequentemente, tornarem-se mais atraentes para os consumidores.

Para proporcionar vantagem competitiva à empresa, a produção deve ser integrada entre si (dentro de suas próprias funções), com as demais funções empresariais e, também, trabalhar focada nos objetivos estratégicos da organização (BACHEGA; GODINHO FILHO, 2005). Assim, Martinez-Olvera (2010), Godinho Filho e Fernandes (2007), Riis et al. (2007), Ketokivi e Heikkilä (2003), Corrêa, Gianesi e Caon (2001) e Slack (1993) apontam a importância das empresas obterem foco estratégico (coerência entre objetivo de desempenho e características do mercado no qual a empresa atua) e coerência entre fins e meios (integração entre objetivos priorizados e princípios/ ferramentas utilizadas pelas empresas).
Baseado neste contexto, identificou-se a seguinte questão de pesquisa: as empresas dos principais polos calçadistas do Estado de São Paulo possuem foco estratégico e/ou consistência entre fins e meios? Assim, a justificativa do problema desta pesquisa apoia-se no fato de que as empresas necessitam usar princípios e ferramentas gerenciais alinhados aos objetivos de desempenho ganhadores de pedidos priorizados e, também, priorizar esses objetivos conforme as características do mercado em que atuam.

Para investigar tal questão, o presente artigo apresenta os resultados de uma pesquisa que teve o objetivo de identificar, por meio de um survey nos três polos calçadistas do Estado de São Paulo (Franca, Birigui e Jaú): a) a presença/ausência de foco estratégico nas empresas; b) a consistência/ inconsistência entre objetivos priorizados e princípios/ ferramentas utilizadas pelas empresas (consistência/ inconsistência entre fins e meios). Essa identificação foi feita utilizando-se o método proposto por Godinho Filho e Fernandes (2007).

O setor calçadista foi escolhido devido ao fato de ser, atualmente, um importante setor da economia do país por seu volume de produção, por sua expressiva participação na pauta de exportações e pela sua capacidade de geração de empregos. Com o acirramento da globalização dos mercados mundiais a partir de 1990, a intensificação da concorrência nos mercados interno e externo fez com que o processo de reestruturação produtiva no setor ganhasse impulso (NAVARRO, 2004). No entanto, a crise econômica mundial também afetou o setor calçadista brasileiro, de forma mais acentuada em algumas empresas exportadoras, tornando ainda mais dinâmico e complexo o cotidiano dos gerentes de produção.

Para cumprir o objetivo, este artigo segue a seguinte estrutura: i) na segunda seção, há a exposição do referencial teórico, com destaque para a apresentação do método de Godinho Filho e Fernandes (2007), que foi utilizado neste trabalho; ii) na terceira seção, são apresentadas informações sobre o survey realizado nos polos de Franca, Birigui e Jaú; iii) na quarta seção, são mostrados os resultados obtidos; iv) por fim, na quinta seção, está a conclusão do trabalho.

\section{Referencial teórico}

Godinho Filho e Fernandes (2009) propuseram o termo 'Paradigmas Estratégicos de Gestão da Manufatura' (PEGEMs), a fim de denominar os paradigmas de gestão existentes atualmente. Esses autores também propuseram um método para determinação do PEGEM utilizado e o ideal (GODINHO FILHO; FERNANDES, 2007). A definição de PEGEM, nas palavras dos autores, é:

Paradigmas Estratégicos de Gestão da Manufatura são [...] modelos/padrões estratégicos e integrados 
de gestão, direcionados a certas situações do mercado, que se propõem a auxiliar as empresas a alcançarem determinado(s) objetivo(s) de desempenho (daí o nome estratégicos). Estes paradigmas são compostos de uma série de princípios e ferramentas (daí a denominação gestão), os quais possibilitam que a empresa, a partir de sua função manufatura (daí a denominação manufatura), atinja tais objetivos, aumentando, desta forma, seu poder competitivo". (GODINHO FILHO; FERNANDES, 2009, p. 148).

A Figura 1 resume as fases do método de Godinho Filho e Fernandes (2007) e sua contribuição para atingir os objetivos deste trabalho. Para verificar se as empresas entrevistadas possuem consistência/ inconsistência entre fins e meios, há a necessidade de se identificar o objetivo de desempenho que a empresa utiliza (etapa 1) e também de se identificarem os princípios/ferramentas que a empresa utiliza (etapa 2). Comparando-se ambas as etapas, pode-se verificar se a empresa está utilizando ferramentas que estão de acordo com seus objetivos (consistência/ inconsistência entre fins e meios). A inconsistência entre fins e meios também pode ser verificada caso não haja predominância de princípios/ferramentas que caracterizem determinado PEGEM na etapa 2.

Para verificar se as empresas estão com/sem foco estratégico, a etapa 1 deve ser comparada com a etapa de identificação do grau de turbulência do mercado em que a empresa está inserida (etapa 3). Dessa forma, consegue-se identificar se a empresa está priorizando objetivo estratégico de acordo com o mercado em que está inserida (presença/ausência de foco estratégico). Cada uma dessas etapas possui elementos que caracterizam dado PEGEM, que são a Manufatura em Massa Atual (MMA), a Manufatura Enxuta (ME), a Manufatura Responsiva (MR), a Customização em Massa (CM) e a Manufatura Ágil (MA).

Nas subseções 2.1, 2.2 e 2.3, são explanadas, respectivamente, as três fases do método utilizado nessa pesquisa.

\subsection{Etapa 1 do método de Godinho Filho e Fernandes (2007)}

Cada PEGEM foca prioritariamente um objetivo estratégico de produção, dito ganhadores de pedidos (objetivos que contribuem diretamente para a realização de um negócio), sendo que outros objetivos, os qualificadores (objetivos nos quais a empresa deve estar acima de um nível determinado para que ela seja inicialmente considerada pelos clientes como uma possível fornecedora), também são importantes. Tal importância, porém, ocorre em uma escala menor, quando os objetivos qualificadores são comparados aos objetivos ganhadores de pedidos. Os termos ganhadores de pedidos e qualificadores foram propostos por Hill (1989).

Os principais PEGEMs, de acordo com Godinho Filho e Fernandes (2009), e seus objetivos ganhadores de pedidos são: Manufatura em Massa Atual (produtividade), Manufatura Enxuta (qualidade), Manufatura Responsiva (responsividade), Customização em Massa (customabilidade) e Manufatura Ágil (agilidade).

A Figura 2 mostra os cinco PEGEMs propostos por Godinho Filho e Fernandes (2009) e seus objetivos ganhadores de pedidos e qualificadores. Nesta figura, os objetivos ganhadores de pedidos são os objetivos explicitados logo abaixo do nome do PEGEM e os objetivos qualificadores são os objetivos explicitados dentro dos retângulos internos ao PEGEM.

Para melhor compreensão deste novo modelo, os seguintes conceitos são importantes (GODINHO FILHO; FERNANDES, 2009, p. 150):

- flexibilidade 1 (ou diferenciação): habilidade do sistema produtivo (SP) responder a mudanças no mix de produtos dentro de uma gama limitada de opções, ou seja, o processo é capaz de fornecer diversidade (pequena variedade de produtos alternativos bastante similares);

- flexibilidade 2 (ou diversidade): habilidade do SP responder a grandes mudanças no mix

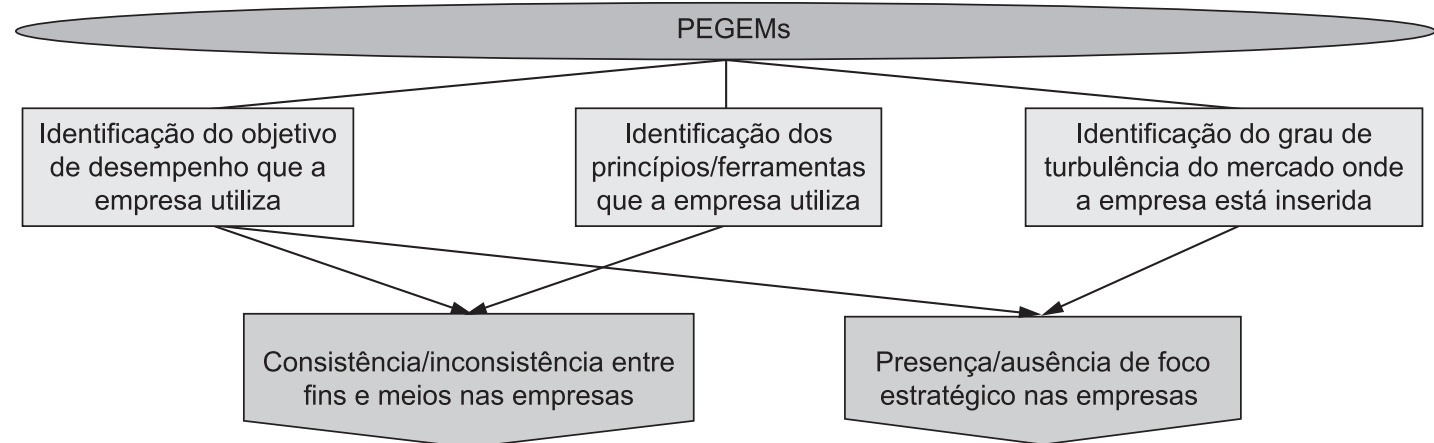

Figura 1. Etapas do método de Godinho Filho e Fernandes (2007) e suas contribuições para os objetivos do trabalho. 
de produtos, ou seja, o processo é capaz de fornecer distinção (grande variedade de produtos distintos);

- qualidade 1 (ou adequação ao uso): habilidade do SP satisfazer a demanda dos consumidores em termos de adequação ao uso;

- qualidade 2 (ou desempenho): habilidade do SP satisfazer a demanda em termos de desempenho ou conformidade a um preço aceitável (abordagem baseada no valor);

- customabilidade: habilidade do SP fornecer soluções individuais para clientes diferenciados dentro de um mix de produtos pré-estabelecido;

- adaptabilidade: habilidade do SP prosperar em um ambiente em constante mudança, caracterizado por inovações tecnológicas e necessidade incessante de lançamento de produtos inéditos.

Na etapa 1 do método de Godinho Filho e Fernandes (2007), é empregado um questionário que usa escala Likert de cinco pontos visando medir a importância dos objetivos estratégicos da produção para a empresa. Assim, a escala atribuída varia de 'proporciona vantagem competitiva crucial junto aos clientes' até 'nunca é considerado pelos clientes e provavelmente nunca será', como pode ser visto no Quadro 1. O grau 1, que representa o objetivo ganhador de pedidos, deve ser atribuído somente a um dos objetivos de desempenho. Os demais graus podem ser atribuídos a mais de um objetivo, de acordo com a realidade da organização.

A importância dada pela empresa a cada um dos objetivos estratégicos e a comparação dessa informação com a Figura 2 fornece indícios sobre o PEGEM que a empresa utiliza.

\subsection{Etapa 2 do método de Godinho Filho e Fernandes (2007)}

Nesta etapa, o método propõe a utilização de uma escala Likert de cinco pontos que mede o grau de importância/utilização de todos os princípios/ ferramentas relativos a cada PEGEM que a empresa utiliza, no intuito de verificar possíveis dificuldades na compreensão da escala e na atribuição dos graus.

Para tanto, empregou-se inicialmente a escala proposta por Godinho Filho e Fernandes (2009). A escala utilizada encontra-se no Quadro 2.

Os princípios/ferramentas de cada PEGEM encontram-se no Quadro 3. Estes estão agrupados de acordo com a aplicabilidade em cada um dos cinco PEGEMs.

O resultado desta etapa é dado pelo grau médio de importância/utilização dos princípios/ferramentas relativos a cada PEGEM. Por meio da escala Likert

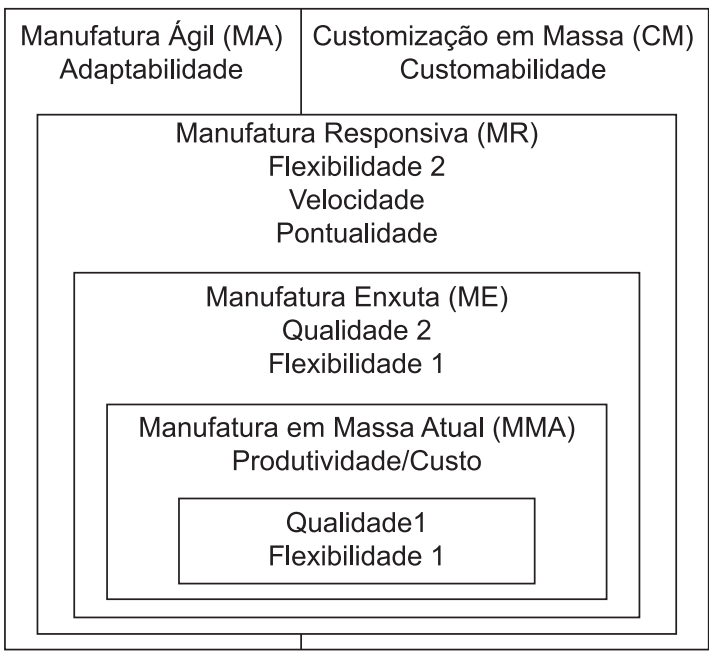

Figura 2. Modelo de relacionamento PEGEM - objetivos estratégicos da manufatura. Fonte: Godinho Filho e Fernandes (2009, p. 154).

Quadro 1. Classificação dos objetivos de desempenho da manufatura de acordo com a escala de cinco pontos.

\begin{tabular}{|c|c|}
\hline Classificação dos objetivos & $\begin{array}{l}\text { Escala para a determinação da importância para os } \\
\text { clientes dos objetivos de desempenho da manufatura }\end{array}$ \\
\hline Ganhadores de pedidos & $\begin{array}{l}1 \text { - o objetivo de desempenho proporciona vantagem competitiva crucial } \\
\text { junto aos clientes. }\end{array}$ \\
\hline \multirow[t]{2}{*}{ Qualificadores } & $\begin{array}{l}2 \text { - o objetivo de desempenho proporciona vantagem competitiva útil } \\
\text { junto à maioria dos clientes. }\end{array}$ \\
\hline & $\begin{array}{l}3 \text { - o objetivo de desempenho precisa estar em torno da média do padrão } \\
\text { do setor industrial. }\end{array}$ \\
\hline \multirow[t]{2}{*}{ Menos importantes } & $\begin{array}{l}4 \text { - o objetivo de desempenho normalmente não é considerado pelos } \\
\text { clientes, mas pode se tornar mais importante no futuro. }\end{array}$ \\
\hline & $\begin{array}{l}5 \text { - o objetivo de desempenho nunca é considerado pelos clientes e } \\
\text { provavelmente nunca será. }\end{array}$ \\
\hline
\end{tabular}

Fonte: Adaptado de Godinho Filho (2009) e Slack (1993). 
utilizada, verifica-se com quais PEGEMs que a empresa mais se relaciona. Salienta-se que este relacionamento deve ser verificado por um valor de médio para alto. Esse valor, de acordo com Godinho Filho e Fernandes (2009), é de no mínimo 3,5.

\subsection{Etapa 3 do método de Godinho Filho e Fernandes (2007)}

Na etapa 3, é usado um mapa de turbulência do mercado elaborado por Godinho Filho e Fernandes (2009) com base nos trabalhos de Pine II (1993) e Sharifi e Zhang (1999). Vinte e três fatores, que podem ser observados no Quadro 4, compõem a análise de turbulência, sendo que o comportamento destes fatores é levantado por meio de um questionário com escala Likert de onze pontos ( 0 a 10$)$, sendo o grau atribuído para cada fator pelos entrevistados. Assim, a percepção da turbulência do mercado pelo entrevistado é maior quando este atribui um grau mais próximo do grau 10.

Coletados os dados sobre estes fatores, realiza-se o somatório dos graus atribuídos nos 23 fatores e compara-se tal valor com a seguinte escala de turbulência: i) turbulência baixa: de 0 a 45; ii) turbulência média-baixa: de 46 a 91; iii) turbulência média: de 92 a 137; iv) turbulência média-alta: de 138 a 183; v) turbulência alta: de 184 a 203. O Quadro 5 aponta a associação entre os PEGEMs e os níveis de turbulência do mercado.

Quadro 2. Escala sobre o grau de importância dos princípios/capacitadores.

\begin{tabular}{|ll|}
\hline Escala de importância que cada princípio/ & 1 - não tem importância alguma/não é utilizado \\
capacitador tem dentro da organização: & 2 - pequena importância/utilização \\
& 3 - média importância/utilização \\
& 4 - muita importância/utilização \\
& 5 -é imprescindível para a empresa/altamente utilizado \\
\hline
\end{tabular}

Fonte: Godinho Filho e Fernandes (2009).

Quadro 3. Princípios/ferramentas por PEGEM.

\begin{tabular}{|c|c|}
\hline PEGEMs & Princípios/ferramentas \\
\hline $\begin{array}{l}\text { Manufatura } \\
\text { em massa atual }\end{array}$ & $\begin{array}{l}\text { i) Foco em clientes sensíveis aos baixos preços; } \\
\text { ii) Foco na padronização do produto, sendo que alguma diferenciação é possível; } \\
\text { iii) Alta eficiência operacional em busca da alta produtividade; e } \\
\text { iv) Alta especialização do trabalho. }\end{array}$ \\
\hline $\begin{array}{l}\text { Manufatura } \\
\text { enxuta }\end{array}$ & $\begin{array}{l}\text { i) Foco na qualidade, com adoção de ferramentas tais como zero defeito, seis sigma, kaizen; } \\
\text { ii) Foco no fornecimento ao cliente de uma ampla diferenciação de produtos, com pouca } \\
\text { diversidade; } \\
\text { iii) Foco na identificação e eliminação de desperdícios, com adoção de ferramentas tais como } \\
\text { Mapeamento do Fluxo de Valor; } \\
\text { iv) Adoção da estratégia de controle da produção just in time, formada por vários princípios } \\
\text { como a produção puxada, entre outros; e } \\
\text { v) Autonomação. }\end{array}$ \\
\hline $\begin{array}{l}\text { Manufatura } \\
\text { responsiva }\end{array}$ & $\begin{array}{l}\text { i) Foco no atendimento aos clientes que priorizam a diversidade de produtos, o tempo de resposta } \\
\text { e o cumprimento de prazos; } \\
\text { ii) Adoção da estratégia de controle da produção que foca a competição baseada no tempo, em } \\
\text { um ambiente de alta variedade de produtos; } \\
\text { iii) Uso de tecnologia voltada à redução do tempo de resposta; e } \\
\text { iv) Fornecimento rápido de produtos e cumprimento de prazos sem grandes estoques. }\end{array}$ \\
\hline $\begin{array}{l}\text { Customização } \\
\text { em massa }\end{array}$ & $\begin{array}{l}\text { i) Foco no atendimento da demanda fragmentada para diferentes gostos e necessidades; } \\
\text { ii) Redução no ciclo de desenvolvimento do produto e também no ciclo de vida dos produtos; } \\
\text { iii) Participação do cliente ao longo das etapas do ciclo de vida dos produtos; e } \\
\text { iv) Tecnologia voltada para a customização e para o contato com o cliente. }\end{array}$ \\
\hline $\begin{array}{l}\text { Manufatura } \\
\text { ágil }\end{array}$ & $\begin{array}{l}\text { i) Foco na identificação de novas e inéditas oportunidades de negócios; } \\
\text { ii) Gestão baseada em competências chave; } \\
\text { iii) Desenvolver habilidades para dominar mudanças e incertezas; } \\
\text { iv) Empresa virtual; e } \\
\text { v) Tecnologia focada em parcerias virtuais. }\end{array}$ \\
\hline
\end{tabular}

Fonte: Godinho Filho e Fernandes (2009, p. 153). 
Quadro 4. Vinte e três fatores que influenciam na turbulência do mercado.

\begin{tabular}{|ll|}
\hline \multicolumn{2}{|c|}{ Fatores que influenciam na turbulência do mercado } \\
\hline Estabilidade e previsibilidade da demanda & Estrutura competitiva \\
Tipos de produtos fornecidos pela empresa & Nível de saturação do mercado \\
Facilidade na identificação das necessidades dos clientes & Vulnerabilidade a produtos substitutos \\
Natureza da demanda & Tamanho e previsibilidade do ciclo dos produtos \\
Taxa de mudança nas necessidades dos clientes & Taxa de mudança tecnológica no produto \\
Mercado com grande percepção nos preço & Introdução de tecnologias completamente novas \\
Mercado com grande percepção na qualidade & Confiabilidade nos fornecedores \\
Mercado com grande percepção na moda & Complexidade no projeto dos produtos da empresa \\
Nível do serviço pré e pós-vendas & Complexidade na manufatura dos produtos \\
Poder de compra dos clientes & Pressões ambientais \\
Grau de influência de ciclos econômicos para a empresa & Poder de resposta dos concorrentes \\
Intensidade competitiva & \\
\hline
\end{tabular}

Fonte: Adaptado de Godinho Filho e Fernandes (2007).

Quadro 5. Associação entre PEGEMs e níveis de turbulência do mercado.

\begin{tabular}{|ll|}
\hline Classificação dos níveis de turbulência do mercado & \multicolumn{1}{c|}{ PEGEMs adequados } \\
\hline Baixa & Manufatura em massa atual/manufatura enxuta \\
Média-baixa & Manufatura enxuta/manufatura responsiva \\
Média & Manufatura responsiva/customização em massa \\
Média-alta & Customização em massa/manufatura ágil \\
Alta & Manufatura ágil \\
\hline
\end{tabular}

Fonte: Godinho Filho e Fernandes (2007).

\subsection{O uso do método de Godinho Filho e Fernandes (2007) para a identificação da falta de foco estratégico e da inconsistência entre fins e meios}

A situação de inconsistência entre fins e meios é apontada quando a etapa 1 do método não possui coerência com a etapa 2 , ou seja, o objetivo estratégico de desempenho da produção ganhador de pedidos priorizado pela empresa não é condizente com os princípios/ferramentas utilizados pela empresa. A inconsistência entre fins e meios também pode ser detectada quando, nos cálculos da etapa 2, a média encontrada não atinge 3,5; portanto, não é identificada a predominância de ferramentas que caracterizam determinado PEGEM.

Ao verificar o nível de turbulência do mercado em que a empresa se encontra, é possível identificar se a empresa está com ou sem foco estratégico por meio da comparação dos resultados das etapas $1 \mathrm{e}$ 3. Portanto, caso estas duas etapas conduzirem ao mesmo PEGEM, este é o mais adequado à realidade da empresa. Se isto não ocorrer, há evidência de que a empresa pode estar priorizando objetivos de desempenho ganhadores de pedidos pouco compatíveis ou incompatíveis com o mercado em que atua, ou seja, configura-se uma ausência de foco estratégico.

\section{O survey realizado nos polos de Franca, Birigui e Jaú}

A presente pesquisa utilizou a explicação científica hipotético-dedutiva, conforme a visão de Carvalho (2000), pois a partir de um problema foram construídas hipóteses que, após a efetuação do trabalho, foram falseadas ou corroboradas. Além disso, a abordagem de pesquisa utilizada foi a quantitativa (BRYMAN, 1989).

Dentre os métodos de pesquisa, Berto e Nakano $(1998 ; 2000)$ apontam os seguintes procedimentos: teórico-conceitual, experimental (CRESWELL, 1994), survey ou também conhecido como pesquisa de avaliação (FREITAS et al., 2000) e pesquisa-ação (THIOLLENT, 1997). Nesta pesquisa, foi utilizado o procedimento teórico-conceitual com o intuito de pré-orientação teórica e também o estudo de caso (YIN, 1994), visando adequar o método proposto por Godinho Filho e Fernandes (2007) com verificações in loco, além de avaliar se o método está pronto para a aplicação em forma de survey nos polos calçadistas. Portanto, o estudo de caso foi utilizado para auxiliar no pré-teste dos questionários usados e, assim, validá-los para a realização do survey. O procedimento de pesquisa survey é detalhado na seção 3.2. 


\subsection{Os polos calçadistas estudados}

No que diz respeito aos principais municípios e polos calçadistas do país, conforme ABICALÇADOS (ASSOCIAÇÃO..., 2009), destacam-se: o polo do Vale dos Sinos (Rio Grande do Sul - considerado o maior cluster de calçados do mundo); o município de São João Batista (Santa Catarina); os polos de Nova Serrana, Belo Horizonte, Uberaba e Uberlândia (Minas Gerais); o município de Goianira (Goiás), no qual está em fase de implantação de um polo calçadista; os polos de Itapetinga, Jequié e Juazeiro (Bahia); os polos de Santa Rita e Campina Grande (Paraíba); os polos de Sobral da região de Fortaleza e da região do Cariri (Ceará), e os polos de Franca, Birigui e Jaú (São Paulo), que constituem o objeto de pesquisa do presente artigo.

Os polos calçadistas de Franca, Birigui e Jaú, localizados no Estado de São Paulo, se destacam. Franca é o maior polo produtor de calçados masculinos do Brasil, sendo integrado por 500 empresas de calçados, que geram cerca de 22,6 mil empregos diretos. Cinquenta países importam os calçados de Franca, resultando em 116,5 milhões de dólares arrecadados pelas organizações deste polo em 2003. O polo de Birigui é constituído por 166 empresas e é considerado o maior produtor de calçados infantis do país. Emprega cerca de 18 mil pessoas e exporta sete milhões de pares por ano. Jaú é um polo especializado na produção de calçados femininos de couro e apresentou um faturamento das exportações em 2003 de 11,5 milhões de dólares. Possui 182 empresas de calçados, que geram 13 mil empregos diretos e cerca de sete mil indiretos (ASSOCIAÇÃO..., 2009).

\subsection{Características gerais do survey}

O método de pesquisa survey (pesquisa de avaliação) foi escolhido devido ao intento de diagnosticar o comportamento de uma população. Uma importante etapa em um survey é o pré-teste do instrumento de pesquisa. Conforme Rea e Parker (2002), o pré-teste possui o objetivo de avaliar alguns fatores, como a clareza, a abrangência e a aceitabilidade do questionário a ser utilizado. Na presente pesquisa, realizou-se o pré-teste do questionário em três empresas, permitindo, assim, a realização de ajustes e complementações do seu conteúdo. O questionário foi aplicado à amostra selecionada apenas depois do pré-teste e das adequações necessárias.

Ressalta-se que foi utilizado o survey supervisionado, no qual o entrevistador faz as perguntas para garantir que cada informante responda a todas elas. Inicialmente, a pesquisa foi conduzida como um survey não supervisionado, mais especificamente um e-mail survey. Devido à restrição de tempo e à não adesão inicial das empresas selecionadas ao e-mail survey, optou-se pelo survey supervisionado.
O survey realizado também possui propósito descritivo, por causa do objetivo de identificar atitudes, eventos e situações manifestos nos polos calçadistas de Franca, Birigui e Jaú, verificando se os fatos estão de acordo com a realidade. A classificação quanto ao momento é por corte transversal ou cross-section, pois foram coletados dados em um só momento e descritas e analisadas as variáveis em um dado momento sem a preocupação de estudar suas evoluções e mudanças. Tais classificações quanto ao propósito e ao momento podem ser encontradas em Pinsonneault e Kraemer (1993) e Sampieri, Collado e Lucio (1991).

Constituíram objeto de estudo deste trabalho, empresas pertencentes ao setor calçadista do Estado de São Paulo, mais especificamente dos polos de Franca (calçados masculinos), Birigui (calçados infantis) e Jaú (calçados femininos). Tais empresas foram escolhidas por meio de amostragem probabilística e aleatória simples, segundo Babbie (1990).

A coleta de dados foi realizada por meio de entrevista, de acordo com Alencar (2000), utilizando-se um questionário estruturado, conforme Forza (2002). Tal coleta perdurou por um ano, sendo a entrevista realizada pessoalmente em cada empresa pelo pesquisador. Foram entrevistados os funcionários de alto escalão (diretor ou gerente de produção/ industrial), com a visão mais abrangente possível das empresas selecionadas. Além deles, no momento da entrevista contou-se com a colaboração de outros funcionários, dentre os quais: proprietário, sócio da empresa, estilista, gerente de custos, diretor/gerente administrativo, gerente de exportação, gerente de tecnologia de informação, planejador e controlador da produção, gerente de administração de pessoal, procurador, e auxiliar de contabilidade. Tal abordagem foi necessária devido à complexidade e à abrangência do método de Godinho Filho e Fernandes (2007), que exige o conhecimento de informações globais, e também para garantir que as respostas refletissem a completa realidade das empresas.

Os questionários estruturados, utilizados na pesquisa, foram baseados no método de identificação do PEGEM utilizado e do paradigma mais adequado, proposto por Godinho Filho e Fernandes (2007).

Os dados quantitativos, coletados por meio dos questionários estruturados, foram tabulados e tratados estatisticamente utilizando-se o software SPSS (Statistical Package for the Social Science) v. 14.0 for Windows (2006).

\subsection{Caracterização da amostra}

A população de empresas calçadistas destas cidades foi obtida por meio dos respectivos sindicatos: SINDIFRANCA (Franca-SP), SINBI (Birigui-SP) e Sindicalçados-Jaú (Jaú-SP). Considerou-se neste estudo apenas as empresas que possuem $100 \mathrm{ou}$ mais funcionários (médio e grande porte) e que 
produzem calçados que caracterizam o respectivo polo, conforme convencionado para aplicação do método de Godinho Filho e Fernandes (2007). Assim, foram identificadas 35 empresas no polo de Franca que produzem calçados masculinos, 33 empresas no polo de Birigui que fabricam calçados infantis e 16 empresas no polo de Jaú que manufaturam calçados femininos, como pode ser verificado na Tabela 1 .

$\mathrm{Na}$ medida em que a população de empresas com cem ou mais funcionários é constituída de 84 empresas no total, foi convencionado um tamanho de amostra de 30 trinta empresas, o que representa $35,7 \%$ da população de empresas com 100 ou mais funcionários.

Caso se utilizasse a amostragem aleatória estratificada, o número de empresas a serem visitadas em cada polo seria: 12 empresas em Franca [(aproximadamente (35/84) \% de 30)], 12 empresas em Birigui e seis empresas em Jaú. Porém, para esta pesquisa, uma amostra de somente cinco ou seis empresas em Jaú seria muito pouco significativa. Nesses casos, de acordo com a literatura, utiliza-se a chamada amostragem aleatória estratificada não proporcional. De acordo com Neuman (2003), esse tipo de amostragem é adequado quando o pesquisador deseja que a proporção de um estrato na amostra seja diferente de sua real proporção na população. Para Rea e Parker (2000), esse tipo de amostragem pode ser utilizado quando o tamanho de amostra de um dos estratos resultante do cálculo da amostra por meio da amostragem estratificada tradicional é muito pequeno. Nesses casos, os autores recomendam que os tamanhos de amostra não proporcionais sejam calculados expandindo-se o tamanho da amostra que não satisfaz um requisito mínimo e reduzindo igualmente o estrato que satisfaz esse requisito. Exatamente isso foi feito no presente estudo: considerou-se que um tamanho de amostra de seis empresas em Jaú seria muito pequeno dada a importância desse polo no Estado de São Paulo. Dessa forma, aumentou-se essa amostra para 10 e reduziu-se o número de empresas a serem entrevistadas em Birigui e Franca. Portanto, resultou-se um tamanho de amostra de 10 empresas por polo, as quais foram sorteadas aleatoriamente.

Como pode ser observado no Quadro 6, o número real de funcionários nas empresas entrevistadas variou de 60 a 2.200. Na fase de coleta de informações sobre as empresas para o processo de amostragem, as empresas selecionadas haviam informado que possuíam 100 ou mais funcionários; mas, no momento da entrevista, cinco empresas afirmaram ter uma quantidade menor do que o previamente convencionado. Estas alegaram que, no período entre o processo de amostragem e a entrevista pessoal, houve demissão em massa de funcionários devido à crise no setor calçadista. Este ponto não foi considerado prejudicial à pesquisa, uma vez que essas empresas possuíam uma estrutura gerencial compatível para a aplicação do método de Godinho Filho e Fernandes (2007).

Dentre as 30 entrevistadas (10 empresas em Jaú, 10 em Franca e 10 em Birigui), 29 responderam o questionário, sendo que a empresa não respondente pertence ao polo de Franca. Das 24 empresas que informaram o faturamento em 2005, 29,2\% (sete empresas) possuíram faturamento de até seis milhões de reais, $29,2 \%$ (sete empresas) estão na faixa acima de seis milhões até 20 milhões de reais, $25 \%$ (seis empresas) estão na faixa acima de 244 mil até 1,2 milhão de reais, $8,2 \%$ (duas empresas) até 244 mil reais, 4,2\% (uma empresa) acima de 50 milhões de reais, e 4,2\% (uma empresa) acima de 20 milhões até 50 milhões de reais, como pode ser visto na Tabela 2.

Tabela 1. Quantidade de empresas por polo calçadista.

\begin{tabular}{lcccc}
\hline Cidade & $\begin{array}{c}\text { Tipo de calçados } \\
\text { fabricados }\end{array}$ & $\begin{array}{c}\text { Número de empresas } \\
(\geq \mathbf{1 0 0} \text { funcionários })\end{array}$ & $\begin{array}{c}\text { Empresas } \\
\text { visitadas }\end{array}$ & $\begin{array}{c}\text { Empresas } \\
\text { respondentes }\end{array}$ \\
\hline Birigui & Infantis & 33 & 10 & 10 \\
Franca & Masculinos & 35 & 10 & 9 \\
Jaú & Femininos & 16 & 10 & 10 \\
Total & & 84 & 30 & 29 \\
\hline
\end{tabular}

Fonte: Dados da pesquisa.

Tabela 2. Faixa de faturamento das empresas.

\begin{tabular}{ccc}
\hline Faturamento & Faixa de faturamento durante 2005 & \% de empresas respondentes \\
\hline 1 & até R \$ 244 mil & 8,2 \\
2 & acima de R \$ 244 mil até R \$ 1,2 milhões & 25 \\
3 & até R \$ 6 milhões & 29,2 \\
4 & acima de R \$ 6 milhões até R \$ 20 milhões & 29,2 \\
5 & acima de R \$ 20 milhões até R \$ 50 milhões & 4,2 \\
6 & acima de 50 milhões & 4,2 \\
\hline
\end{tabular}

Fonte: Dados da pesquisa. 


\section{Resultados obtidos}

Nesta seção, são expostos os objetivos de desempenho, os princípios/ferramentas e os graus de turbulência identificados no survey realizado.

\subsection{Objetivos de desempenho identificados}

As percentagens e as frequências dos objetivos de desempenho identificados nos polos de Birigui, Franca e Jaú estão explicitadas, respectivamente, nas Tabelas 3, 4 e 5. No polo de Birigui, o objetivo ganhador de pedidos mais citado foi a diversidade (30\%) e os objetivos qualificadores mais citados nos graus 2 e 3 foram, respectivamente, a pontualidade $(19,4 \%)$ e a adaptabilidade $(26,7 \%)$. Já o objetivo menos importante mais citado, nos graus 4 e 5 , foi a diferenciação (66,7\% e 100\%, respectivamente).

No polo de Franca, os objetivos de desempenho mais citados foram: i) ganhadores de pedidos: custo $(33,3 \%)$ e diferenciação $(33,3 \%)$;ii) qualificadores: desempenho $(21,2 \%)$ e pontualidade $(21,2 \%)$ no grau 2, e adaptabilidade (20\%) no grau 3; iii) menos importantes: rapidez $(33,3 \%)$, diversidade $(33,3 \%) \mathrm{e}$ customabilidade $(33,3 \%)$ no grau 4 , e customabilidade $(50 \%)$ e adaptabilidade (50\%) no grau 5 (Tabela 4$)$.

As maiores percentagens dos objetivos identificados nas empresas entrevistadas no polo de Jaú, conforme indica a Tabela 5, foram: $40 \%$ para o custo como objetivo ganhador de pedidos; $18,6 \%$ para a pontualidade como objetivo qualificador de grau $2 ; 19,1 \%$ para a adaptabilidade como objetivo qualificador de grau 3, e $60 \%$ para a customabilidade como objetivo menos importante de grau 4.

A Figura 3 expõe a representação polar dos objetivos ganhadores de pedidos, indicando que, no polo de Jaú, o objetivo custo é mais priorizado; em Franca, os objetivos custo e diferenciação possuem importância em igual escala e, em Birigui, a diversidade. Verifica-se, também, que o objetivo adaptabilidade não é ganhador de pedidos, o que pode indicar uma possível tendência no setor calçadista do Estado de São Paulo.

Cabe ressaltar que, de acordo com as modificações realizadas no método de Godinho Filho e Fernandes (2007) para aplicação em um survey, as empresas entrevistadas deveriam marcar apenas um objetivo como ganhador de pedidos (grau 1 de importância), sendo que nos demais graus classificados como qualificadores e menos importantes, os respondentes poderiam repetir o grau atribuído para mais de um objetivo.

\subsection{Princípios/ferramentas identificados}

Na etapa 2, por meio da análise dos princípios/ ferramentas que as empresas entrevistadas utilizam, os possíveis PEGEMs indicados no polo de Birigui com as respectivas percentagens foram, considerando-se os dez entrevistados: i) somente Manufatura Enxuta: 10\% das empresas; ii) somente Manufatura Responsiva: 20\%; iii) apenas Customização em Massa: 10\%; iv) falta de predominância de princípios/ferramentas relativos a determinado PEGEM, ou seja, a média encontrada não atingiu 3,5: 20\%; v) Manufatura em Massa

Quadro 6. Alguns resultados da pesquisa.

Da amostra

- $100 \%$ das empresas são empresas limitadas.

- $100 \%$ das empresas são de capital nacional.

- Número de trabalhadores varia de 60 a 2200, sendo que 1 empresa não informou.

- Número de trabalhadores na produção varia de 40 a 1900, sendo que 2 empresas não informaram.

Fonte: Dados da pesquisa.

Tabela 3. Objetivos estratégicos de desempenho da produção no polo de Birigui.

\begin{tabular}{cccrrrr}
\hline \multirow{2}{*}{ Polo } & Objetivos de & \multicolumn{2}{c}{ Ganhadores de pedidos } & \multicolumn{2}{c}{ Qualificadores } & \multicolumn{2}{c}{ Menos importantes } \\
\cline { 3 - 7 } desempenho & Grau 1 & Grau 2 & Grau 3 & Grau 4 & Grau 5 \\
\hline Birigui & Custo & $20 \%(2)$ & $16,7 \%(6)$ & $6,7 \%(2)$ & $0 \%(0)$ & $0 \%(0)$ \\
& Desempenho & $10 \%(1)$ & $11,1 \%(4)$ & $16,7 \%(5)$ & $0 \%(0)$ & $0 \%(0)$ \\
& Diferenciação & $10 \%(1)$ & $5,6 \%(2)$ & $10 \%(3)$ & $66,7 \%(2)$ & $100 \%(2)$ \\
& Rapidez & $10 \%(1)$ & $16,7 \%(6)$ & $10 \%(3)$ & $0 \%(0)$ & $0 \%(0)$ \\
& Pontualidade & $20 \%(2)$ & $19,4 \%(7)$ & $3,3 \%(1)$ & $0 \%(0)$ & $0 \%(0)$ \\
& Diversidade & $30 \%(3)$ & $11,1 \%(4)$ & $10 \%(3)$ & $0 \%(0)$ & $0 \%(0)$ \\
& Customabilidade & $0 \%(0)$ & $13,9 \%(5)$ & $16,7 \%(5)$ & $0 \%(0)$ & $0 \%(0)$ \\
& Adaptabilidade & $0 \%(0)$ & $5,6 \%(2)$ & $26,7 \%(8)$ & $33,3 \%(1)$ & $0 \%(0)$ \\
& Total de citações & $100 \%(10)$ & $100 \%(36)$ & $100 \%(30)$ & $100 \%(3)$ & $100 \%(2)$ \\
\hline
\end{tabular}

Fonte: Dados da pesquisa. 


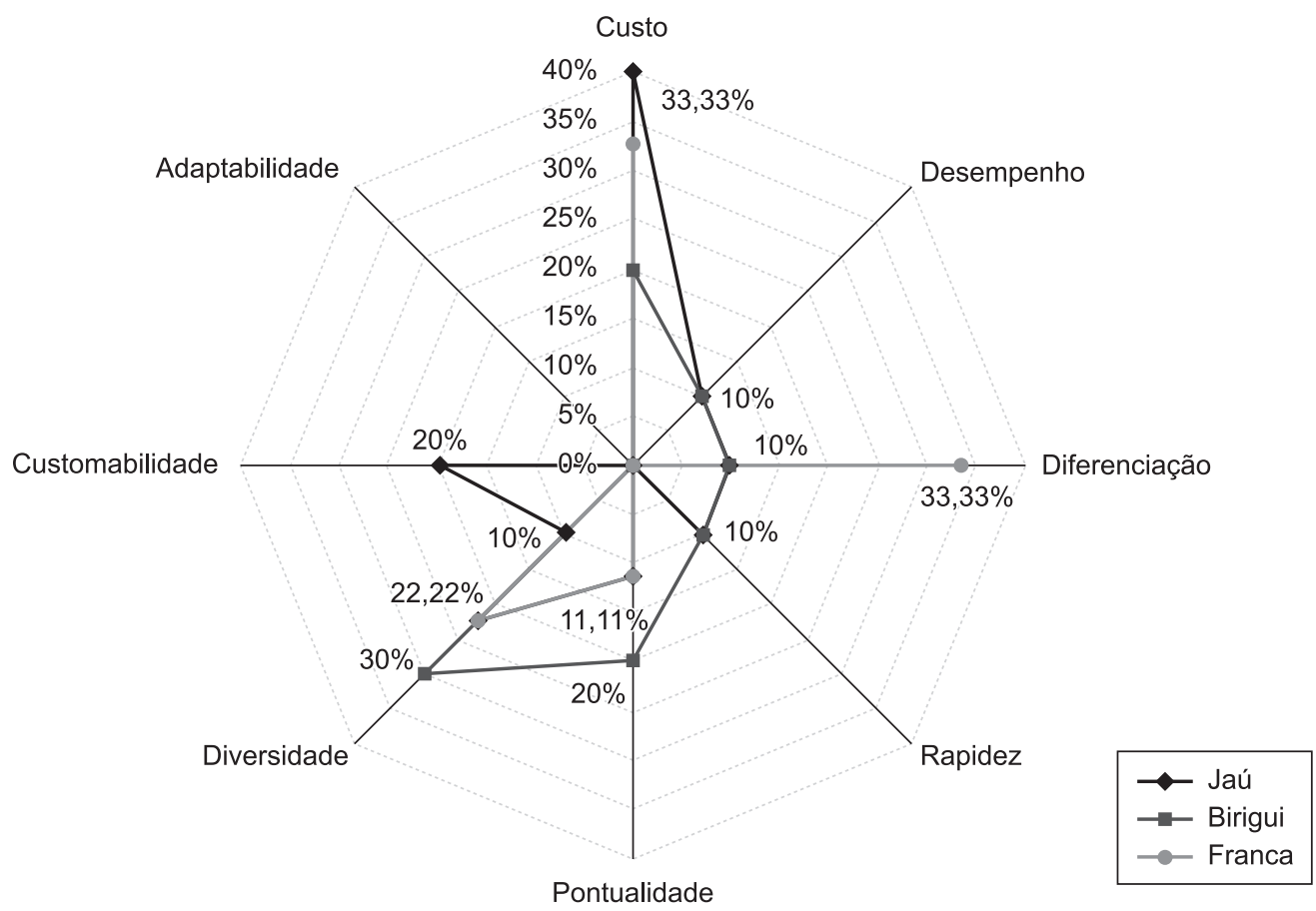

Figura 3. Representação polar dos objetivos ganhadores de pedidos nos três polos. Fonte: Dados da pesquisa.

Tabela 4. Objetivos estratégicos de desempenho da produção no polo de Franca.

\begin{tabular}{|c|c|c|c|c|c|c|}
\hline \multirow[t]{2}{*}{ Polo } & \multirow{2}{*}{$\begin{array}{l}\text { Objetivos de } \\
\text { desempenho }\end{array}$} & \multirow{2}{*}{$\begin{array}{c}\begin{array}{c}\text { Ganhadores de } \\
\text { pedidos }\end{array} \\
\text { Grau } 1 \\
\end{array}$} & \multicolumn{2}{|c|}{ Qualificadores } & \multicolumn{2}{|c|}{ Menos importantes } \\
\hline & & & Grau 2 & Grau 3 & Grau 4 & Grau 5 \\
\hline \multirow[t]{9}{*}{ Franca } & Custo & $33,3 \%(3)$ & $9,1 \%(3)$ & $12 \%(3)$ & $0 \%(0)$ & $0 \%(0)$ \\
\hline & Desempenho & $0 \%(0)$ & $21,2 \%(7)$ & $8 \%(2)$ & $0 \%(0)$ & $0 \%(0)$ \\
\hline & Diferenciação & $33,3 \%$ (3) & $6,1 \%(2)$ & $16 \%(4)$ & $0 \%(0)$ & $0 \%(0)$ \\
\hline & Rapidez & $0 \%(0)$ & $15,1 \%(5)$ & $8 \%(2)$ & $33,3 \%(1)$ & $0 \%(0)$ \\
\hline & Pontualidade & $11,1 \%(1)$ & $21,2 \%(7)$ & $8 \%(2)$ & $0 \%(0)$ & $0 \%(0)$ \\
\hline & Diversidade & $22,2 \%(2)$ & $9,1 \%(3)$ & $12 \%(3)$ & $33,3 \%(1)$ & $0 \%(0)$ \\
\hline & Customabilidade & $0 \%(0)$ & $6,1 \%(2)$ & $16 \%(4)$ & $33,3 \%(1)$ & $50 \%(1)$ \\
\hline & Adaptabilidade & $0 \%(0)$ & $12,1 \%(4)$ & $20 \%(5)$ & $0 \%(0)$ & $50 \%(1)$ \\
\hline & Total de citações & $100 \%(9)$ & $100 \%(33)$ & $100 \%(25)$ & $100 \%(3)$ & $100 \%(2)$ \\
\hline
\end{tabular}

Fonte: Dados da pesquisa.

Tabela 5. Objetivos estratégicos de desempenho da produção no polo de Jaú.

\begin{tabular}{cccrrrr}
\hline \multirow{2}{*}{ Polo } & Objetivos de & & Ganhadores de pedidos & \multicolumn{2}{c}{ Qualificadores } & \multicolumn{2}{c}{ Menos importantes } \\
\cline { 3 - 7 } desempenho & Grau 1 & Grau 2 & Grau 3 & Grau 4 & Grau 5 \\
\hline Jaú & Custo & $40 \%(4)$ & $7 \%(3)$ & $14,3 \%(3)$ & $0 \%(0)$ & $0 \%(0)$ \\
& Desempenho & $10 \%(1)$ & $13,9 \%(6)$ & $14,3 \%(3)$ & $0 \%(0)$ & $0 \%(0)$ \\
& Diferenciação & $10 \%(1)$ & $11,6 \%(5)$ & $14,3 \%(3)$ & $20 \%(1)$ & $0 \%(0)$ \\
Rapidez & $10 \%(1)$ & $16,3 \%(7)$ & $9,5 \%(2)$ & $0 \%(0)$ & $0 \%(0)$ \\
& Pontualidade & $0 \%(0)$ & $18,6 \%(8)$ & $9,5 \%(2)$ & $0 \%(0)$ & $0 \%(0)$ \\
& Diversidade & $10 \%(1)$ & $16,3 \%(7)$ & $9,5 \%(2)$ & $0 \%(0)$ & $0 \%(0)$ \\
& Customabilidade & $20 \%(2)$ & $7 \%(3)$ & $9,5 \%(2)$ & $60 \%(3)$ & $0 \%(0)$ \\
Adaptabilidade & $0 \%(0)$ & $9,3 \%(4)$ & $19,1 \%(4)$ & $20 \%(1)$ & $0 \%(0)$ \\
& Total de citações & $100 \%(10)$ & $100 \%(43)$ & $100 \%(21)$ & $100 \%(5)$ & $0 \%(0)$ \\
\hline
\end{tabular}


Atual e Manufatura Responsiva, simultaneamente: $10 \%$; vi) Manufatura Enxuta concomitante com Manufatura Responsiva: 10\%; vii) Manufatura em Massa Atual simultânea a Customização em Massa: 10\%; viii) Manufatura em Massa Atual concomitante com Manufatura Enxuta, Manufatura Responsiva e Customização em Massa: 10\%. Tais dados podem ser observados na Tabela 6 .

No polo de Franca, dos nove respondentes, $11,1 \%$ não utilizam ferramentas em dados graus que caracterizem algum PEGEM; 55,6\% apresentaram indícios de Manufatura Responsiva e 33,3\% apresentam Manufatura Responsiva e Customização em Massa. No entanto, dos dez entrevistados em Jaú, com situações de nenhum PEGEM identificado, somente Manufatura Responsiva, apenas Customização em Massa, e Manufatura em Massa Atual e Manufatura Responsiva, cada uma obteve $20 \%$ de manifestação. Já a Manufatura Enxuta concomitante com Manufatura Responsiva, e Manufatura Responsiva com Customização em Massa, ambas as manifestações apresentam $10 \%$ das respostas.

As situações comuns aos três polos são a possível presença de somente Manufatura Responsiva e a falta de predominância de princípios/ferramentas que caracterizem algum PEGEM. Além disso, das 37 identificações de presença de possíveis PEGEMs nas empresas entrevistadas, verificou-se que cinco empresas utilizam fortemente princípios/ferramentas da MMA, 18 empresas usam com maior intensidade princípios/ferramentas da MR e dez empresas empregam princípios/ferramentas da CM. Cabe ressaltar que não foi identificado o forte uso de princípios/ferramentas da MA nos polos estudados.

Ao se considerar cada polo separadamente, em Birigui houve 14 identificações de presença de possíveis PEGEMs nas empresas entrevistadas. A MR foi manifestada cinco vezes (35,7\%); a MMA, a ME e a CM foram identificadas três vezes cada uma, ou seja, 21,4\% das identificações cada. No polo de Franca, apenas a MR e a CM apareceram dentre as 11 identificações de possíveis PEGEMs, totalizando respectivamente oito $(72,7 \%)$ e três $(27,3 \%)$ vezes. Em Jaú, a MMA foi identificada duas vezes $(16,7 \%)$ como possível PEGEM, a ME obteve uma aparição $(8,3 \%)$, a MR teve cinco manifestações $(41,7 \%)$ e a $\mathrm{CM}$ apareceu quatro vezes $(33,3 \%)$.

\subsection{Graus de turbulência identificados}

Observa-se na Tabela 7 que a grande maioria das empresas se encontra em ambiente com níveis de turbulência de médio (92 a 137) a médio-alto (138 a 183). Somente no polo de Jaú, foi encontrado indício $(10 \%)$ de turbulência média-baixa (46 a 91).

No polo de Franca, 66,7\% dos nove respondentes se enquadraram no grau de turbulência média-alta e 33,3\% no grau de turbulência média. Em Birigui,

Tabela 6. Princípios/ferramentas que a empresa utiliza.

\begin{tabular}{|c|c|c|c|}
\hline PEGEMs/Polos & Birigui & Franca & Jaú \\
\hline Falta de predominância & $20 \%(2)$ & $11,1 \%(1)$ & $20 \%(2)$ \\
\hline $\mathrm{ME}$ & $10 \%(1)$ & $0 \%(0)$ & $0 \%(0)$ \\
\hline MR & $20 \%(2)$ & $55,6 \%(5)$ & $20 \%(2)$ \\
\hline $\mathrm{CM}$ & $10 \%(1)$ & $0 \%(0)$ & $20 \%(2)$ \\
\hline $\mathrm{MMA} \times \mathrm{MR}$ & $10 \%(1)$ & $0 \%(0)$ & $20 \%(2)$ \\
\hline $\mathrm{ME} \times \mathrm{MR}$ & $10 \%(1)$ & $0 \%(0)$ & $0 \%(0)$ \\
\hline $\mathrm{MMA} \times \mathrm{CM}$ & $10 \%(1)$ & $0 \%(0)$ & $0 \%(0)$ \\
\hline $\mathrm{ME} \times \mathrm{CM}$ & $0 \%(0)$ & $0 \%(0)$ & $10 \%(1)$ \\
\hline $\mathrm{MR} \times \mathrm{CM}$ & $0 \%(0)$ & $33,3 \%(3)$ & $10 \%(1)$ \\
\hline $\mathrm{MMA} \times \mathrm{ME} \times \mathrm{MR} \times \mathrm{CM}$ & $10 \%(1)$ & $0 \%(0)$ & $0 \%(0)$ \\
\hline Total de citações & $100 \%(10)$ & $100 \%(9)$ & $100 \%(10)$ \\
\hline
\end{tabular}

Fonte: Dados da pesquisa.

Tabela 7. Grau de turbulência do mercado.

\begin{tabular}{lrrr}
\hline Graus de turbulência/Polos & Birigui & Franca & Jaú \\
\hline Turbulência baixa (0 a 45) & $0 \%(0)$ & $0 \%(0)$ & $0 \%(0)$ \\
Turbulência média-baixa (46 a 91) & $0 \%(0)$ & $0 \%(0)$ & $10 \%(1)$ \\
Turbulência média (92 a 137) & $50 \%(5)$ & $33,3 \%(3)$ & $40 \%(4)$ \\
Turbulência média-alta (138 a 183) & $50 \%(5)$ & $66,7 \%(6)$ & $50 \%(5)$ \\
Turbulência alta (184 a 230) & $0 \%(0)$ & $0 \%(0)$ & $0 \%(0)$ \\
Total de citações & $100 \%(10)$ & $100 \%(9)$ & $100 \%(10)$ \\
\hline
\end{tabular}

Fonte: Dados da pesquisa. 
encontrou-se $50 \%$ de empresas com turbulência média e $50 \%$ de empresas com turbulência média-alta. Já no polo de Jaú, a predominância foi de turbulência média alta com $50 \%$ dos indicativos, seguida de $40 \%$ de turbulência média e $10 \%$ de turbulência média-baixa.

\subsection{A identificação de foco estratégico e de consistência entre fins e meios}

As Tabelas 8, 9 e 10 expõem, para os três polos pesquisados, os resultados encontrados durante a identificação de presença/ausência de foco estratégico e consistência/inconsistência entre fins e meios.

Para a verificação da consistência/inconsistência entre fins e meios, foram confrontados os resultados obtidos na Etapa 1 com os resultados da Etapa 2, conforme o método utilizado. Caso os princípios/ ferramentas utilizados pelas empresas (etapa 2) sejam coerentes com os objetivos de desempenho ganhadores de pedidos seguidos por essas empresas (etapa 1), estas se encontram em situação de consistência entre fins e meios. Caso contrário, a empresa encontra-se em situação de inconsistência entre fins e meios, ou seja, utiliza fundamentos, métodos, ferramentas e técnicas não alinhados com o objetivo de desempenho ganhador de pedidos almejado. Essa situação também é verificada quando há falta de predominância de princípios/ferramentas relativos a determinado PEGEM na etapa 2.

Quanto à identificação de presença/ausência de foco estratégico, esta foi obtida pela comparação dos resultados obtidos na Etapa 1 com os resultados obtidos na Etapa 3. Em outras palavras, se o objetivo de desempenho (etapa 1) priorizado pela empresa está de acordo com o ambiente em que a empresa está inserida (medido pelo grau de turbulência - etapa 3), então esta se encontra em situação de presença de foco estratégico. Caso contrário, a empresa se encontra em situação de ausência de foco estratégico, ou seja, a empresa prioriza determinado objetivo ganhador de pedidos pouco compatível ou incompatível com o mercado em que atua.

Assim, uma empresa que se encontra em situação de inconsistência entre fins e meios utiliza princípios e ferramentas gerenciais que não convergem, total ou parcialmente, apara o alcance do objetivo de desempenho ganhador de pedidos. Já, na situação de ausência de foco estratégico, a empresa possui pouco conhecimento ou desconhece as características do mercado onde em que atua e enfoca um objetivo ganhador de pedidos divergente. Essas situações podem implicar diretamente na pouca ou não realização de negócios em uma empresa e, consequentemente, na não sustentação e/ou aquisição de vantagens competitivas. Como pode ser observado na Tabela 8 , somente $20 \%$ das empresas entrevistadas em Jaú (duas empresas) apresentam consistência entre fins e meios e 40\% das empresas (quatro empresas) possuem foco estratégico. Considerando-se ambos os aspectos de forma conjunta, $60 \%$ das empresas (seis empresas) encontram-se na situação de inconsistência entre fins e meios e ausência de foco estratégico, $20 \%$ (duas empresas) possuem inconsistência entre fins e meios e presença de foco estratégico, e $20 \%$ (duas empresas) apresentam consistência entre fins e meios e presença de foco estratégico.

Por intermédio da Tabela 9, é possível verificar as seguintes situações no polo de Franca, dentre os nove respondentes: i) 22,2\% das empresas (duas empresas) apresentam consistência entre fins e meios; ii) $22,2 \%$ das empresas (duas empresas) apresentam falta de foco estratégico. Além disso, considerando-se ambos os aspectos de forma conjunta: i) $66,7 \%$ das empresas (seis empresas) encontram-se na situação de inconsistência entre fins e meios, e ausência de foco estratégico; ii) $11,1 \%$ (uma empresa) possui inconsistência entre fins e meios, e presença de foco estratégico; iii) $11,1 \%$ (uma empresa) apresenta consistência entre fins e meios, e presença de foco estratégico; e iv) 11,1\% (uma empresa) está em situação de consistência entre fins e meios, e ausência de foco estratégico.

As situações encontradas nas empresas entrevistadas no polo de Birigui estão na Tabela 10. Como pode ser notado, apenas $20 \%$ das empresas (duas empresas) apresentam consistência entre fins e meios e $30 \%$ das empresas (três empresas) possuem foco estratégico. Outros pontos observados quando se consideram ambos os aspectos de forma conjunta: i) $60 \%$ das empresas (seis empresas) encontram-se na situação de inconsistência entre fins e meios, e ausência de foco estratégico; ii) $20 \%$ (duas empresas) possuem inconsistência entre fins e meios, e presença de foco estratégico; iii) $10 \%$ (uma empresa) apresenta consistência entre fins e meios, e presença de foco estratégico; e iv) $10 \%$ (uma empresa) está em situação de consistência entre fins e meios, e ausência de foco estratégico.

Quando os três polos calçadistas são tratados conjuntamente, tem-se que, dentre os respondentes, apenas 20,7\% (seis empresas) apresentam consistência entre fins e meios, e $31 \%$ (nove empresas) estão em situação de presença de foco estratégico. De acordo com a percentagem válida presente na Tabela 11 , 62,1\% das empresas está em situação de inconsistência entre fins e meios, e ausência de foco estratégico; $17,2 \%$ apresentam inconsistência entre fins e meios, e presença de foco estratégico; $6,9 \%$ das empresas apresentam consistência entre fins e meios, e ausência de foco estratégico, e somente $13,8 \%$ das empresas encontram-se em situação de consistência entre fins e meios, e presença de foco estratégico. 

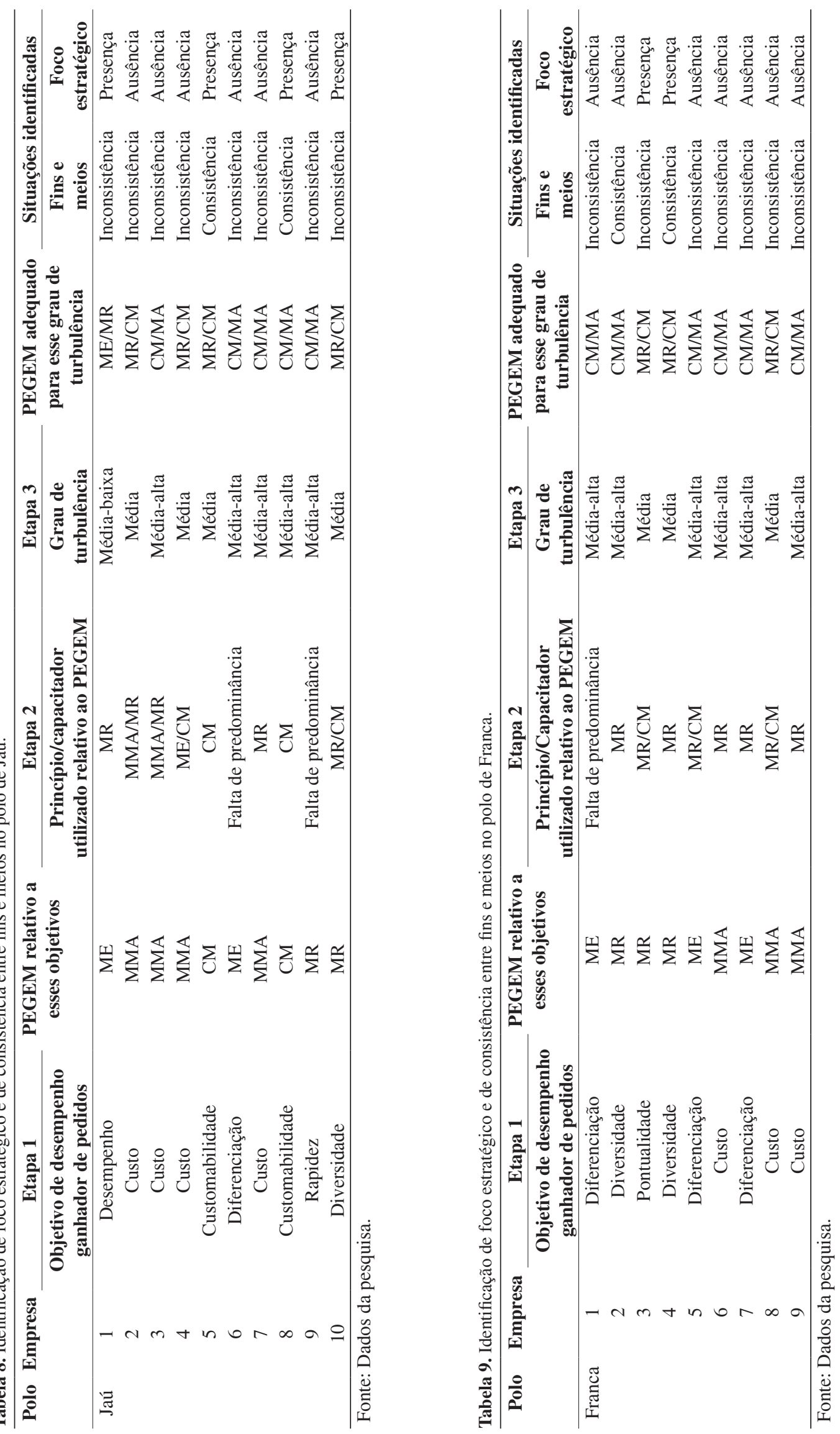

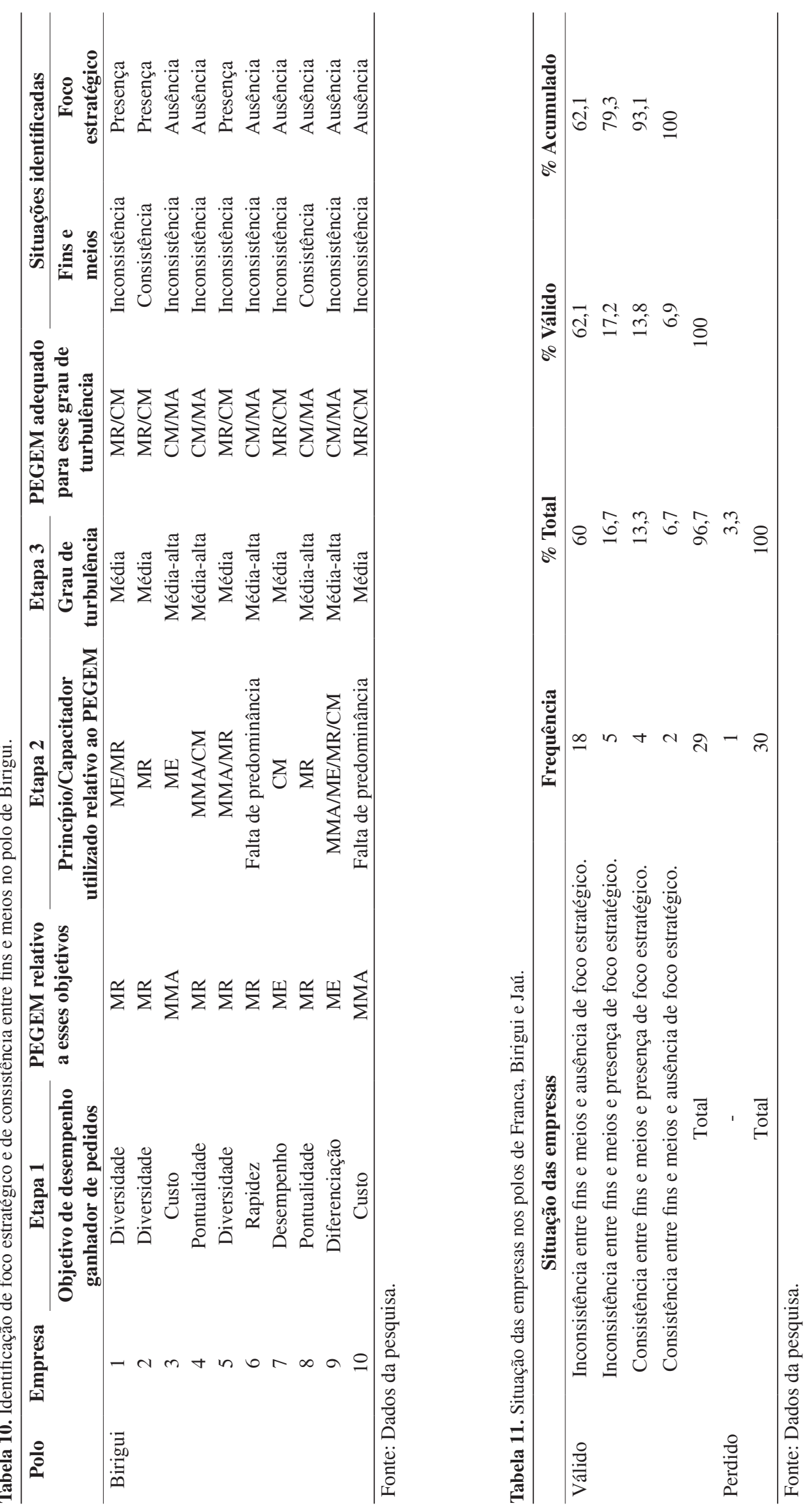


\section{Conclusão}

O objetivo do presente artigo foi atingido. Identificou-se, por meio de um survey nos polos calçadistas de Franca, Birigui e Jaú, a presença/ ausência de foco estratégico nas empresas e a consistência/inconsistência entre fins e meios. Cabe ressaltar que esta pesquisa não permite a generalização dos resultados para toda a população, mas sim, aponta possíveis tendências de comportamento das empresas pesquisadas.

Por meio da pesquisa realizada, foi identificado que $69 \%$ das empresas calçadistas entrevistadas (vinte empresas) encontram-se sem foco estratégico e 79,3\% dos respondentes (23 empresas) apresentam inconsistência entre fins e meios. Além disso, $62,1 \%$ dessas empresas (18 empresas) estão em ambas as situações (inconsistência entre fins e meios, e ausência de foco estratégico). Ao analisar separadamente a situação das empresas entrevistadas de cada polo, a maioria das empresas apresenta ausência de foco estratégico e inconsistência entre fins e meios.

Também foi identificado que os princípios/ ferramentas mais utilizados pelas empresas participantes da pesquisa são relativos aos seguintes paradigmas: manufatura responsiva, presente em 18 empresas, e customização em massa, presente em 10 empresas. Também foram identificados princípios/ ferramentas voltados à manufatura enxuta e à manufatura em massa atual.

Algumas proposições podem ser alçadas por meio desse fato observado:

- A percepção de maiores graus de turbulência do mercado pelos gestores das empresas calçadistas estudadas pode favorecer a adoção de grande diversidade de princípios, ferramentas, técnicas e métodos, na tentativa de melhor gerir os negócios e de atender a demanda;

- Os gestores das empresas participantes da pesquisa podem ter dificuldade em priorizar um objetivo de desempenho ganhador de pedidos mais adequado para o grau de turbulência do mercado e também em utilizar princípios/ ferramentas mais afins com o objetivo priorizado.

Salienta-se, novamente, que a inconsistência entre fins e meios, e a falta de foco estratégico podem prejudicar a manutenção e/ou aquisição de vantagens competitivas pelas empresas devido a pouca ou não realização de negócios em uma empresa.

Esta pesquisa apresenta como contribuição o alerta para a existência de falta de foco estratégico e de situações de inconsistência entre fins e meios em empresas do setor calçadista. Essas informações são importantes para o setor coureiro-calçadista, que apresenta um histórico de crise, indicando a necessidade das empresas se reestruturarem estratégica e gerencialmente para encontrarem um 'norte' e, assim, sobreviverem neste ambiente cada vez mais dinâmico e competitivo. Ademais, este trabalho motiva a realização de novas pesquisas do tipo survey com o intuito de generalização dos resultados encontrados para o setor como um todo.

Como se trata de uma pesquisa inédita quanto à aplicação do método de Godinho Filho e Fernandes (2007) em uma pesquisa do tipo survey, sugerem-se, para pesquisas futuras, aplicações do método em pesquisas de avaliação tanto no mesmo setor, com intuito de comparar outros polos, ou até mesmo analisar o setor em âmbitos nacional/internacional. Caso haja algumas modificações no questionário, substituindo as partes peculiares às empresas produtoras de calçados, o método poderá ser aplicado nos demais setores da economia. Também sugere-se a realização de pesquisas com o intuito de corroborar ou refutar as proposições levantadas neste trabalho.

\section{Agradecimentos}

À Coordenação de Aperfeiçoamento de Pessoal de Nível Superior (CAPES), pela concessão de Bolsa, e à Fundação de Amparo à Pesquisa do Estado de São Paulo (FAPESP), pelo suporte financeiro concedido durante o desenvolvimento deste trabalho.

\section{Referências}

ASSOCIAÇÃO BRASILEIRA DAS INDÚSTRIAS DE CALÇADOS - ABICALÇADOS. Disponível em: <http:// www.abicalcados.com.br>. Acesso em: 14 abr. 2009.

ALENCAR, E. Introdução à metodologia de pesquisa social. Lavras: UFLA/FAEPE, 2000. 105 p.

ANSOFF, H. I. A nova estratégia empresarial. São Paulo: Atlas, 1990. $265 \mathrm{p}$.

BABBIE, E. Métodos de pesquisas de survey. Belo Horizonte: Editora UFMG, 2001. 519 p.

BACHEGA, S. J. ; GODINHO FILHO, M. Caracterização dos tipos de integração atualmente existentes na literatura de gestão da manufatura. In: SIMPÓSIO DE ENGENHARIA DE PRODUÇÃO, 12., 2005, Bauru. Anais... Bauru: SIMPEP, 2005.

BERTO, R. M. V. S.; NAKANO, D. N. Metodologia da pesquisa e a engenharia de produção.In: XVIII ENCONTRO NACIONAL DE ENGENHARIA DE PRODUÇÃO - ENEGEP, 18.; INTERNATIONAL CONGRESS OF INDUSTRIAL ENGINEERING - ICIE, 6., 1998, Niterói. Anais... Niterói: UFF/ABEPRO, 1998. 1 CD-ROM.

BERTO, R. M. V. S.; NAKANO, D. N. A produção científica nos anais do encontro nacional de engenharia de produção: um levantamento dos métodos e tipos de pesquisa. Produção, v. 9, n. 2, p. 65-75, 2000. http:// dx.doi.org/10.1590/S0103-65131999000200005

BRYMAN, A. Research methods and organization studies. London: Uniwin Hyman, 1989. 224 p. http:// dx.doi.org/10.4324/9780203359648 
CARVALHO, M. C. M. A construção do saber científico: algumas proposições. In: CARVALHO, M. C. M. (Org.). Construindo o saber. 2. ed. Campinas: Papirus, 2000. p.63-86.

CHRISTENSEN, K. H. Estratégia Corporativa: Gerenciando um Conjunto de Negócios. In: FAHEY, L.; RANDALL, R. M. MBA Curso Prático: Estratégia. 2. ed. Rio de Janeiro: Campus, 1999. p. 67-99.

CORRÊA, H. L. Just in time, MRP II e OPT: um enfoque estratégico. São Paulo: Atlas, 1993. 186 p.

CORRÊA, H. L.; GIANESI, I. G. N.; CAON, M. Planejamento, programação e controle da produção. 4. ed. São Paulo: Atlas, 2001. 456 p.

CRESWELL, J. W. Research design: qualitative \& quantitative approaches. London: Sage, 1994. 248 p.

FORZA, C. Survey research in operations management: a process-based perspective. International Journal of Operations \& Production Management, v. 22, n. 2, p. 152-194, 2002. http://dx.doi. org/10.1108/01443570210414310

FREITAS, H. et al. O método de pesquisa survey. Revista de Administração, v. 35, n. 3, p.105-112, 2000.

GIMENEZ, F. A. P. O estrategista na pequena empresa. Maringá: Universidade Estadual de Maringá, 2000. 176 p.

GODINHO FILHO, M. Paradigmas Estratégicos de Gestão da Manufatura: configuração, relações com o planejamento e controle da produção e estudo exploratório na indústria de calçados. 2004. 267 f. Tese (Doutorado em Engenharia de Produção)-Universidade Federal de São Carlos, São Carlos, 2004.

GODINHO FILHO, M.; FERNANDES, F. C. F. Paradigmas Estratégicos de Gestão da Manufatura: identificação, prescrição e estudo de casos na indústria de calçados. Revista de Administração USP, v. 42 n. 3, p. 349-362, 2007.

GODINHO FILHO, M.; FERNANDES, F. C. F. Strategic Paradigms for Manufacturing Management (SPMM): Key Elements and Conceptual Model. International Journal of Industrial Engineering, v. 16, p. 147-159, 2009.

GUPTA, A. K. Estratégia das unidades de negócios: gerenciando um único negócio. In: FAHEY, L.; RANDALL, R. M. MBA curso prático: estratégia. 2. ed. Rio de Janeiro: Campus, 1999. p. 100-125.

HALLGREN, M.; OLHAGER, J. Differentiating manufacturing focus. International Journal of Production Research, v. 44, n. 18-19, p. 3863-3878, 2006. http://dx.doi.org/10.1080/00207540600702290

HARRISON, J. S. Administração estratégica de recursos e relacionamentos. Porto Alegre: Bookman, 2004.

HAYES, R. H.; WHEELWRIGHT, S. C. Restoring our competitive edge: competing through manufacturing. New York: John Wiley \& Sons, 1984. 427 p.

HENDERSON, B. D. As origens da estratégia. In: MONTGOMERY, C. A.; PORTER M. E. Estratégia: a busca da vantagem competitiva. Rio de Janeiro: Campus, 1998. parte I, cap. 1, p. 3-9.

HILL, T. Manufacturing strategy: text \& cases. 2. ed. Burr Ridge: IRWIN, 1994. 578 p.

KETOKIVI, M.; HEIKKILÄ, J. A strategic management system for manufacturing: Linking action to performance. Production Planning and Control, v. 14, n. 6, p.
487-496, 2003. http://dx.doi.org/10.1080/095372803 10001621958

MARTINEZ-OLVERA, C. Impact of the alignment between the strategic and operational levels of a manufacturing enterprise.International Journal of Production Research, v. 48, n. 4, p. 1195-1215, 2010. http://dx.doi.org/10.1080/00207540802534723

MINTZBERG, H. A criação artesanal da estratégia. In: MONTGOMERY, C. A.; PORTER M. E. Estratégia: a busca da vantagem competitiva. Rio de Janeiro: Campus, 1998. parte V, cap. 4, p. 419-437.

MINTZBERG, H. Five Ps for strategy. In: MINTZBERG, H.; QUINN, J. B. The strategy process, concepts, contexts, cases. 2. ed. Upper Saddle River: PrenticeHall, 1991. p. 12.

MINTZBERG, H.; QUINN, J. B. O processo da estratégia. 3. ed. Porto Alegre: Bookman, 2001. 404 p.

NAVARRO, V. L. Reestruturação produtiva e precarização do trabalho na indústria de calçados no Brasil. In: CONFERÊNCIA INTERNACIONAL LA OBRA DE CARLOS MARX Y LOS DESAFÍOS DEL SIGLO XXI, 2., 2004, Havana. Anales... Havana, 2004. Disponível em: <http://www.nodo50.org/cubasigloXXI/congreso04/ navarro_290204.pdf>. Acesso em: 19 dez. 2004.

NEUMAN, W. L. Social Research Methods. 5th ed. New York: Allyn and Bacon, 2003

OLIVEIRA, D.P. R. Planejamento estratégico. 15. ed. São Paulo: Atlas, 2001. 303 p.

PATAH, L. A.; CARVALHO, M. M. Alinhamento entre estrutura organizacional de projetos e estratégia de manufatura: uma análise comparativa de múltiplos casos. Gestão da Produção, 2009, v. 16, n. 2, p. 301-312. http://dx.doi.org/10.1590/S0104-530X2009000200012

PEREIRA, G. M.; SELLITTO, M. A.; BORCHARDT, M. Alterações nos fatores de competição da indústria calçadista exportadora devido à entrada de competidores asiáticos. Produção, v. 20, n. 2, 2010, p. 149-159, 2010. http://dx.doi.org/10.1590/S0103-65132010005000022

PINSONNEAULT, A.; KRAEMER, K. L. Survey research in management information systems: an assessement. Journal of Management Information System, v. 10, n. 2, p. 75-105, 1993.

PIRES, S. Gestão estratégica da produção. Piracicaba: UNIMEP, 1995. $270 \mathrm{p}$.

PORTER, M. E. Competição: estratégias competitivas essenciais. 4. ed. Rio de Janeiro: Campus, 1999.

PORTER, M. E. Estratégia competitiva: técnicas para análises de indústrias e da concorrência. 7. ed. Rio de Janeiro: Campus, 1997. 362 p.

PORTER, M. E. Vantagem competitiva: criando e sustentando um desempenho superior. Rio de Janeiro: Campus, 1989. 512 p.

REA, L.M.; PARKER, R.A. Metodologia de pesquisa: do planejamento à execução. São Paulo: Pioneira Thomson Learning, 2002. 262 p.

RIIS, J. O. et al. Strategic roles of manufacturing. Journal of Manufacturing Technology Management, v. 18, n. 8 , p. 933-948, 2007. http://dx.doi. org/10.1108/17410380710828262 
SAMPIERI, R. H.; COLLADO, F. C.; LUCIO, B. P. Metodología de la investigación. México: McGrawHill, 1991.

SKINNER, W. Manufacturing: the Formidable Competitive Weapon, John Wiley \& Sons, New York, 1985.

SLACK, N. Vantagem competitiva em manufatura. Atlas: São Paulo, 1993. 224 p.

SLACK, N. et al. Administração da Produção. São Paulo: Atlas, 2002. 747 p.

STATISTICAL PACKAGE FOR THE SOCIAL SCIENCE SPSS. v. 14.0 for Windows. Free trial version. Disponível em:<http://www.spss.com>. Acesso em: set. 2006.
THIOLLENT, M. J. M. Pesquisa-ação em organizações. São Paulo: Atlas, 1997.

THOMPSON JUNIOR, A. A.; STRICKLAND III, A. J. Planejamento estratégico: elaboração, implementação e execução. São Paulo: Pioneira, 2002. 431 p.

WRIGHT, P.; KROLL, M.; PARNELL, L. Administração estratégica: conceitos. São Paulo: Atlas, 2000.

ZACCARELLI, S. B. Estratégia e sucesso nas empresas. São Paulo: Saraiva, 2000. 244 p.

YIN, R.K. Case study research: design and methods. Newbury Park, California: Sage Publications, 1994. $166 \mathrm{p}$. 